\title{
Deodorization of Ammonia by Coffee Grounds
}

\author{
Naohito Kawasaki ${ }^{* 1}$, Hideo KInoshita ${ }^{2}$, Takashi OuE ${ }^{2}$, Takeo NaKamura ${ }^{1}$ \\ and Seiki TANADA ${ }^{1}$ \\ ${ }^{1}$ School of Pharmaceutical Sciences, Kinki University \\ (3-4-1 Kowakae, Higashi-Osaka, Osaka 577-8502, JAPAN) \\ ${ }^{2}$ Kokubu Hospital \\ (4-672 Asahigaoka, Kashihara, Osaka 582-0026, JAPAN)
}

Edited by J. Sekiya, Kyoto Univ., and accepted August 12, 2005 (received for review March 7, 2005)

\begin{abstract}
Coffee grounds are a vegetable biomass that can be efficiently burned. The carbon dioxide generated by burning coffee grounds is affecting global warming. On the other hand, ammonia generated in the places such as toilets or farms produces a bad smell. In the present study, we have analyzed the possibility of ammonia elimination using the carbonaceous materials produced from coffee grounds. Carbonaceous materials were prepared by the microwave treatment of coffee grounds. We observed that the saturated amounts of ammonia adsorbed by some of the carbonaceous materials produced from coffee grounds were greater than that adsorbed by activated carbon. In contrast, the activated carbon adsorption rate for ammonia was higher than those of the carbonaceous materials. Therefore, carbonaceous materials produced from coffee grounds could be utilized for the removal of ammonia in the gaseous phase.
\end{abstract}

Key words: adsorption rate, ammonia, coffee ground, vegetable biomass

\section{Introduction}

In recent years, we have been required to think about environmental problems on a global scale. Current socio-economic activities such as mass production, mass consumption and mass abandonment are all related to consumption. The amount of waste has increased due to the development of these activities. Moreover, most vegetable biomasses are being burned, leading to a global warming generated by excessive accumulation of atmospheric carbon dioxide. The amount of carbon dioxide discharge linked to Japanese economic activities will be restricted by enforcement of the Kyoto Protocol, an amendment to the United Nations Framework Convention on Climate Change. Therefore, to enable the society to continue advancing, it is necessary to qualify the organic wastes as if they were "unused organic materials", and to develop the technology for promoting material circulation. Organizing a carbon circulation-type society is especially required. Coffee grounds are vegetable biomass being burned for disposal, but they will have to be reused in a circulation-type society. We have already reported lead, dyes and formaldehyde removal by coffee grounds based toxic removal technologies (1-3). In these studies, the activated carbons were prepared from coffee grounds and rice hulls by chemical activation using sodium hydroxide, potassium hydroxide and zinc chloride (4). Besides, the production of adsorbents from Sugi sapwood was achieved by oxygen-nitrogen activation (5). However, chemical activation is not good because there is the danger of environmental pollution.

Ammonia, which is generated in places such as toilets or farms, has a strange odor and its environmental

\footnotetext{
*Correspondence to: Naohito KAWASAKI, School of Pharmaceutical Sciences, Kinki University, 3-4-1 Kowakae, Higashi-Osaka, Osaka 5778502, JAPAN

E-mail: kawasaki@phar.kindai.ac.jp
} 
concentration is being controlled by the Offensive Odor Control Law in Japan. Ammonia is a polar molecule which is difficult to eliminate using activated carbon because the activated carbon surface is hydrophobic.

In this study, coffee grounds have been regarded as a useful unused material, and the possibility to use them following their carbonization was examined. The carbonaceous materials from coffee grounds were prepared by the microwave treatment, and the adsorption of ammonia onto the carbonaceous materials was examined based on the amount of ammonia adsorbed at the saturation level, the adsorption rate, and the physicochemical properties of the carbonaceous materials.

\section{Materials and Methods}

\subsection{Materials}

The aqueous ammonia solution was purchased from Wako Pure Chemical Industries, Ltd. Activated carbon (AC) made from steam-activated coconut shell, Shirasagi $\mathrm{G}$ was obtained from Takeda Chemical Industries, Ltd. Coffee grounds used here were originated from beans of Coffea robusta produced in Thailand. Carbonaceous materials of coffee grounds, CG0, CG10, CG15 and CG20, were prepared by carbonizing the wetted coffee grounds in air by the microwave treatment for $0,10,15$ and $20 \mathrm{~min}$ at $2450 \mathrm{MHz}$ and the output of $500 \mathrm{~W}$, respectively. All carbonaceous adsorbents (AC, CG0, CG10, CG15 and CG20) were dried for $15 \mathrm{~h}$ at $190^{\circ} \mathrm{C}$ before use.

\section{$2 \cdot 2$ Acid and Base Consumption of $\mathrm{AC}$ and CGs}

Acid and base consumptions by the AC and CGs were measured using the acid-base titration method (6). The AC or CGs were added to $100 \mathrm{~mL}$ of an aqueous hydrochloric acid solution $(0.1 \mathrm{~mol} / \mathrm{L})$, and the suspension was shaken for $15 \mathrm{~h}$. The base consumption was determined by titrating the filtered solution with an aqueous sodium hydroxide solution $(0.1 \mathrm{~mol} / \mathrm{L})$. On the other hand, either the AC or CGs were added to $100 \mathrm{~mL}$ of an aqueous sodium hydroxide solution $(0.1 \mathrm{~mol} / \mathrm{L})$, and the suspension was shaken for $15 \mathrm{~h}$. The acid consumption was determined by titrating with an aqueous hydrochloric acid solution $(0.1 \mathrm{~mol} / \mathrm{L})$.

\subsection{Specific Surface Area of AC and CGs}

The $\mathrm{AC}$ and CGs were dried for $3 \mathrm{~h}$ at $190^{\circ} \mathrm{C}$. The specific surface area of the carbonaceous materials was measured using a FlowSorb II 2300 (Micromeritics Co., Ltd.).

\subsection{Saturated Amount of Ammonia Adsorbed by AC and CGs}

Approximately $0.1 \mathrm{~g}$ of either the $\mathrm{AC}$ or CGs was placed in a weigh bottle and stored in a desiccator containing a $35 \%$ ammonia aqueous solution in a $100-\mathrm{mL}$ beaker for $72 \mathrm{~h}$ at 15 or $25^{\circ} \mathrm{C}$. The saturated amount of ammonia adsorbed by the $\mathrm{AC}$ and CGs was estimated from their weight before and after the adsorption. The weight was measured using an A\&D GR-120 electronic balance.

\subsection{Adsorption Rate of Ammonia by AC and CGs}

The device to determine the adsorption of ammonia by the AC and CGs is shown in Fig. 1. The concentration of ammonia in the absorption liquid was deter-

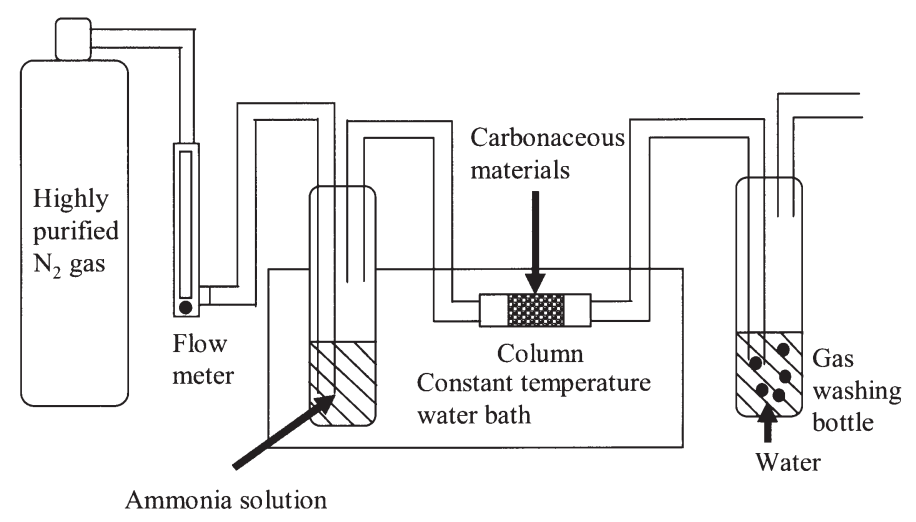

Fig. 1 Device to Determine Adsorption of Ammonia. 
mined by the standard analytical method for hygiene chemists, that is, the indophenol method (7). A $5.0 \mathrm{~mL}$ sample was added to a test tube along with $2.5 \mathrm{~mL}$ of a phenol sodium nitroprusside aqueous solution and 2.5 $\mathrm{mL}$ of a $\mathrm{NaClO}$ aqueous solution, which then was incubated for $60 \mathrm{~min}$ at $25^{\circ} \mathrm{C}$. The ammonia was measured at the maximum absorbance wavelength $(640 \mathrm{~nm})$ using a Hitachi U-1100 spectrophotometer (Hitachi Ltd.), with water as the blank, and $\mathrm{NH}_{4} \mathrm{Cl}$ as the standard for the calibration curve.

\section{Results}

The base and acid consumptions of the AC or CGs and the yield of the carbonaceous material by the microwave treatment are shown in Table 1. The acid consumption of the AC and CGs were similar. In contrast, the base consumption of $\mathrm{AC}$ was the lowest and that of CG0 was the highest, and having a value 8 times greater than that of AC. Results of the elemental analysis and measurements of the specific surface area of the AC and CGs are shown in Table 2. The N/C values of the CGs did not change by the microwave treatment, but the $\mathrm{H} / \mathrm{C}$ values decreased. The specific surface area of the CGs is lower than that of $\mathrm{AC}$ due to the lack of activation.

The saturated amounts of ammonia adsorbed by the AC and CGs are shown in Table 3. The amounts of adsorbed ammonia increased in the following order: CG20, CG15, AC, CG10 and CG0. The amounts of ammonia adsorbed at $15^{\circ} \mathrm{C}$ were greater than those adsorbed at $25^{\circ} \mathrm{C}$, and the difference increased with the longer microwave treatment. In spite of AC and CG0 having the highest and the lowest specific surface areas, the saturated amounts of ammonia adsorbed by $\mathrm{AC}$ and CG0 resulted in the lowest and highest values, respectively.

The amount of ammonia adsorbed by CG0 did not increase with the longer microwave treatment. The amount of ammonia adsorbed by CG15 is lower than that by AC. However, the saturated amount of ammonia adsorbed by CG0 was twice as much compared to that adsorbed by AC.

The amounts of ammonia adsorbed by the AC and CGs versus time are shown in Fig. 2. The adsorption rate of ammonia increased in the order of CG10, CG20 or CG15, CG0 and AC. The ammonia adsorption by $\mathrm{AC}$ reached an equilibrium after $8 \mathrm{~min}$. We believed
Table 1 Physical and Chemical Properties of Carbonaceous Materials.

\begin{tabular}{lrcc}
\hline \multirow{2}{*}{ Sample } & \multicolumn{2}{c}{ Consumption $(\mathrm{mmol} / \mathrm{g})$} & \multirow{2}{*}{ Yield (\%) } \\
\cline { 2 - 3 } & Base & Acid & \\
\hline AC & 1.4 & 0.048 & - \\
CG 0 & 11.7 & 0.040 & - \\
CG 10 & 5.0 & 0.032 & 25.5 \\
CG 15 & 7.8 & 0.049 & 6.9 \\
CG 20 & 8.2 & 0.058 & 5.3 \\
\hline
\end{tabular}

a) (Weight of carbonaceous material after carbonization/weight of wetted coffee grounds) $\times 100$.

Table 2 Physical and Chemical Properties of Carbonaceous Materials.

\begin{tabular}{lccc}
\hline Sample & $\mathrm{N} / \mathrm{C}^{\mathrm{a})}$ & $\mathrm{H} / \mathrm{C}^{\mathrm{b})}$ & Specific surface area $\left(\mathrm{m}^{2} / \mathrm{g}\right)$ \\
\hline AC & --- & --- & 1119 \\
CG 0 & 4.3 & 12.6 & $<1$ \\
CG10 & 4.3 & 9.7 & $<1$ \\
CG 15 & 4.5 & 4.5 & $<1$ \\
CG 20 & 4.1 & 2.6 & 5 \\
\hline
\end{tabular}

a) $\{\mathrm{N}($ nitrogen content, \%)/C (carbon content, \%) $\} \times 100$

b) $\{\mathrm{H}$ (hydrogen content, \%) $/ \mathrm{C}$ (carbon content, \%) $\} \times 100$

Table 3 Saturated Amounts of Ammonia Adsorbed onto Carbonaceous Materials.

\begin{tabular}{lccc}
\hline \multirow{2}{*}{ Sample } & \multicolumn{2}{c}{ S.A.A $(\mathrm{mg} / \mathrm{g})^{\mathrm{a})}$} & \multirow{2}{*}{ A.P $(\%)^{\mathrm{b})}$} \\
\cline { 2 - 3 } & $15^{\circ} \mathrm{C}$ & $25^{\circ} \mathrm{C}$ & \\
\hline $\mathrm{AC}$ & 234 & 181 & 77 \\
$\mathrm{CG} 0$ & 606 & 365 & 60 \\
$\mathrm{CG} 10$ & 508 & 275 & 54 \\
$\mathrm{CG} 15$ & 175 & 86 & 49 \\
$\mathrm{CG} 20$ & 145 & 68 & 47 \\
\hline
\end{tabular}

a) Saturated amount of ammonia adsorbed.

b) (Amount of ammonia adsorbed at $25^{\circ} \mathrm{C} /$ amount of ammonia adsorbed at $\left.15^{\circ} \mathrm{C}\right) \times 100$. 


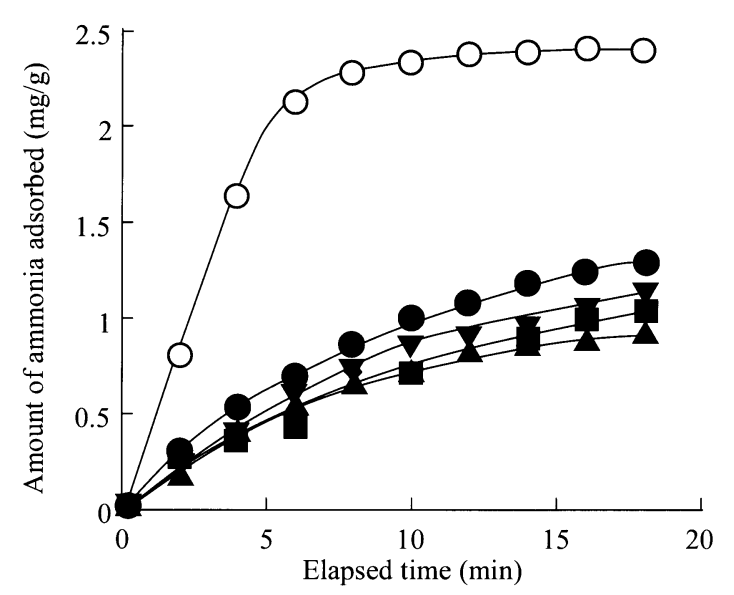

Fig. 2 Amount of Ammonia Adsorbed onto Carbonaceous Materials vs. Time.

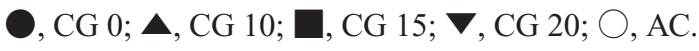

Table 4 Adsorption Rate Constants of Carbonaceous Materials for Ammonia.

\begin{tabular}{ccc}
\hline Sample & $\begin{array}{c}\text { Adsorption rate constant }{ }^{\mathrm{a})} \\
\left(\times 10^{-3} \mathrm{mg} / \mathrm{g} / \mathrm{min}\right)\end{array}$ & $\mathrm{r}^{\mathrm{b})}$ \\
\hline AC & 2.72 & 1.000 \\
CG 0 & 0.14 & 0.988 \\
CG 10 & 0.25 & 1.000 \\
CG 15 & 0.13 & 0.988 \\
CG 20 & 0.59 & 1.000 \\
\hline a) Adsorption rate constants were obtained based on Samejima's \\
equation. \\
b) Correlation coefficient.
\end{tabular}

that the results shown in Fig. 2 followed Samejima's equation, which is an adsorption rate equation derived from the Langmuir adsorption rate equation. For the early stage of adsorption, Samejima's equation (8) takes the following form:

$$
V e \times \operatorname{Ln}\{\mathrm{Ve} /(\mathrm{Ve}-\mathrm{V})\}-V=k t
$$

where $t$ is the elapsed time in minutes, $V e$ and $V$ represent the milligram amount of adsorbate adsorbed per gram of adsorbent at equilibrium and at a given time $t$, respectively, and $k$ is the adsorption rate constant expressed in $\mathrm{mg} / \mathrm{g} / \mathrm{min}$. Equation [1] is represented by a straight line when $[\mathrm{Ve} \times \operatorname{Ln}\{\mathrm{Ve} /(\mathrm{Ve}-\mathrm{V})\}-V]$ is plotted versus $t$, and the adsorption rate constant $k$ is given by the slope of the line. The adsorption rate constant and the correlation coefficient are shown in Table 4. The experimental results fit to the Samejima's equa- tion yielding the regression lines

$[\mathrm{Ve} \times \operatorname{Ln}\{\mathrm{Ve} /(\mathrm{Ve}-\mathrm{V})\}-\mathrm{V}]$ versus time for $t<5$ min with correlation coefficients from 0.988 to 1.000 . From the slopes of these lines, the adsorption rate constants of the different CGs were estimated to be from 0.13 to $0.59 \mathrm{mg} / \mathrm{g} / \mathrm{min}$, while the $\mathrm{AC}$ adsorption rate constant was $2.72 \mathrm{mg} / \mathrm{g} / \mathrm{min}$.

\section{Discussion}

The production of activated carbon includes both carbonization and activation processes. In general, based on the carbonization process using a rotary kiln or an electric muffle furnace employs an output power of $1500 \mathrm{~W}$ and a period of $150 \mathrm{~min}$. For the microwave treatment, the output power and the period were $500 \mathrm{~W}$ and $15 \mathrm{~min}$, respectively. The amounts of electricity needed to manufacture the carbonaceous materials by carbonization using an electric muffle furnace and a microwave apparatus are $3750 \mathrm{Wh}$ and $125 \mathrm{Wh}$, respectively. The Ministry of Environment reported in 1999 that the amount of carbon dioxide produced per kilowatt-hour was $0.550 \mathrm{~kg}$. According with this, the amount of carbon dioxide produced by the electric muffle furnace and the microwave apparatus is $2.06 \mathrm{~kg}$ and $0.07 \mathrm{~kg}$, respectively. Results of elemental analysis were used to evaluate the carbon dioxide discharge associated to carbonization of the CGs.

Acid consumptions by the AC and CGs were similar. In contrast, the CG0 base consumption is the highest, being about 8 times greater than that of the AC. Base and acid consumptions by the adsorbents indicate the number of carboxyl or phenolic hydroxyl groups and the number of amino groups on the adsorbent's surface, respectively (6). The number of $\mathrm{AC}$ and $\mathrm{CGs}$ amino groups did not change. In contrast, the number of carboxyl or phenolic hydroxyl groups changed. The yield of CG10 by microwave treatment is the highest. However, it decreased with an increasing the treatment period due to the occurrence of excessive carbonization.

The saturated amounts of ammonia adsorbed increased in the order CG20, CG15, AC, CG10 and CG0. In addition, the saturated amount of ammonia adsorbed at $15^{\circ} \mathrm{C}$ was greater than at $25^{\circ} \mathrm{C}$. The saturated amount adsorbed at $15^{\circ} \mathrm{C}$ compared to that at $25^{\circ} \mathrm{C}$ decreased with the increasing microwave treatment period. Thus, ammonia adsorption abilities of the AC and CGs might be related with the adsorbent's physical 
properties. CG0 had the highest level of base consumption, and therefore it could easily adsorb the base materials. In spite of the fact the specific surface area of $\mathrm{AC}$ and CG0 were the highest and the lowest, their saturated amounts of ammonia adsorbed were the lowest and the highest, respectively.

In general, the removal of hazardous materials by adsorbents is better when the absorption rate is faster. However, the adsorbents with a faster adsorption rate sometimes cannot be used for a long time. In spite of the fact that the CG0 adsorption rate was slower than that of $\mathrm{AC}$, the saturated amounts of ammonia adsorbed by $\mathrm{CG} 0$ and $\mathrm{CG} 10$ was greater than that adsorbed by AC. Hence, CG0 and CG10 can be used as deodorants for a much longer time than $\mathrm{AC}$.

\section{References}

1. T. TOKIMOTO, N. KAWASAKI, T. NAKAMURA, J. AKUTAGAWA and S. TANADA, Removal of Lead Ions in Drinking Water by Coffee Grounds as Vegetable Biomass, J. Colloid Interface Sci., Vol. 281, 56-61 (2005).

2. M. HIRATA, N. KAWASAKI, T. NAKAMURA, K. MAT-
SUMOTO, M. KABAYAMA, T. TAMURA and S. TANADA, Adsorption of Dyes onto Carbonaceous Materials Produced from Coffee Grounds by Microwave Treatment, J. Colloid Interface Sci., Vol. 254, 17-22 (2002).

3. M. HIRATA, N. KAWASAKI, T. NAKAMURA, R. BUNEI and S. TANADA, Removal of Formaldehyde by Surface-Modified Carbonaceous Materials, Hyomen Kagaku, Vol. 24, 417-422 (2003).

4. H.H. KIM, R.H. PARK and Y.J. KIM, Preparation of Activated Carbons Using Biomass, Kongap Hwahak, Vol. 15, 870-874 (2004).

5. K. SUGAmOTO, Y. MATSUSitA, S. FUJimoto and M. TAKANO, Carbonization of Wood Biomass: Formation of Charcoal Having Acidic Groups by Carbonization of Sugi Sapwood under Oxygen-Nitrogen Atmosphere, Tanso, Vol. 212, 69-74 (2004).

6. S. SUGANO, S. FUKUI, S. NAOTO and M. KANEKO, Analysis by Indophenol Method, J. Hygienic Chem., Vol. 14, 280-286 (1968).

7. K. OGINO, Surface Modification of Carbon Adsorbents and their Adsorption Characteristics. Surface Chemical Structure and Adsorption, Adsorpt. News, Vol. 4, 4-10 (1990).

8. J. SAMEJIMA, Sorption Velocity of Gas by Poroussolid, Bull. Chem. Soc. Jpn., Vol. 7, 177-188 (1932). 